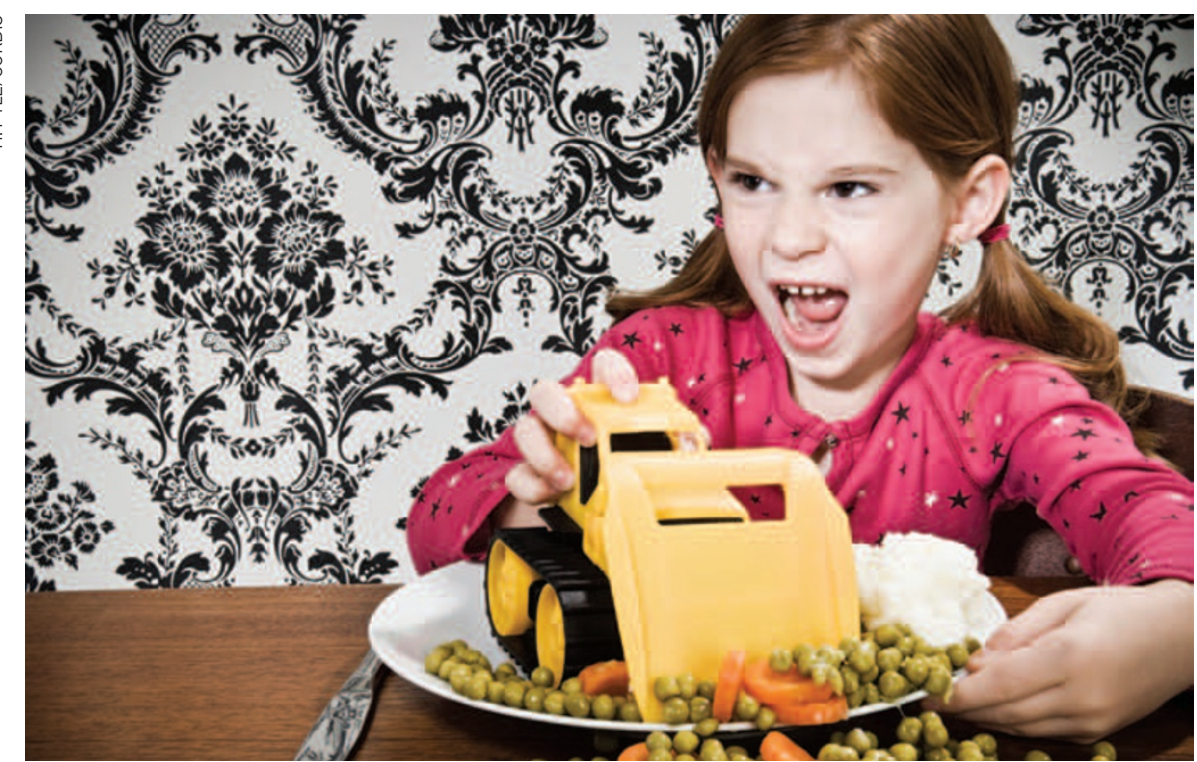

PSYCHOLOGY

\title{
More alike than different
}

\section{Two books debunk gender differences in the brain, discovers Virginia Valian.}

\section{$\mathrm{T}$} rying to distinguish the female from the male brain is a trap that many writers fall into. Two books provide a welcome corrective by reviewing scientific evidence showing that the sexes are more alike than different, and that small sex differences are not fixed but change with context and across generations.

Cordelia Fine's Delusions of Gender is aimed at a broad audience and debunks the egregious exaggerations common in popular books. Rebecca Jordan-Young's Brain Storm is directed at specialists who are interested in historical studies of the brain, sex hormones and gender differences. Fine, a psychologist at Macquarie University in Sydney, Australia, and Jordan-Young, a medical sociologist at Barnard College in New York, point out the methodological and theoretical limitations of such studies, and demonstrate the part that folk theories about gender differences have played in casting the sexes as inherently dichotomous.

Both books note that correlation and causation are often confused when looking at the results of brain or hormonal differences on behaviour - 'causing', for example, boys to be better than girls at mental rotation of threedimensional objects. Too many studies ignore mediating variables and alternative explanations and exaggerate the extent of gender differences. Both accounts direct attention to the full range of results, including those that researchers might otherwise ignore.
Delusions of Gender: How Our Minds, Society, and Neurosexism Create

Difference/The Real Science Behind Sex Differences

CORDELIA FINE

W. W. Norton/Icon Books: 2010.338 pp./368 pp. $\$ 25.95 / £ 14.99$

Brain Storm: The Flaws in the Science of Sex Differences

REBECCA M. JORDAN-YOUNG

Harvard University Press: 2010.408 pp. $\$ 35$

Although males and females differ in many ways, the authors note that the same could be said of any two groups - people with different hair colour or degrees of economic security, say. Because men and women have distinct reproductive functions, controlled in part by different hormones, we are prone to interpret their behavioural and psychological differences as not only biologically mediated but mandated. Putative brain differences are seized on as sex-based and other hypotheses can be overlooked.

To illustrate, Fine considers the corpus callosum linking the two brain hemispheres. The fact that it seems to be thicker in women than in men is sometimes associated with women's supposed greater verbal skill. According to $\rightarrow$ NATURE.COM Neurobiologist Ben Barres on gender and science:

go.nature.com/pdogax this 'just-so' reasoning, a thicker corpus callosum may allow easier integration of information from the two sides of the brain.
But, as both authors point out, the reported differences in corpus callosum size are unreliable between studies, and seem to be related to brain size. In both sexes, larger brains have a larger callosum, but in smaller brains they make up a greater percentage of brain volume. So if a sex difference in the corpus callosum exists, it is likely to be a by-product of the basic difference in average brain size - a fact that is missed by a focus on sex. Unless researchers conduct analyses that divide groups in ways other than gender, the real story might be missed.

The behaviours of both sexes are remarkably similar despite their presumed brain and hormonal differences. Although men's brains are roughly $10 \%$ larger than women's, the IQs of both genders are roughly equal, and most experiments in cognitive processing in children and adults reveal no sex differences.

In deflating spurious claims about the influences on sex differences, the books risk underestimating those effects. Consider congenital adrenal hyperplasia (CAH), a major topic in Jordan-Young's book, in which the fetus is exposed to higher levels of androgens than are unaffected children. This causes emotional and physical symptoms ranging in girls from early-onset puberty to infertility. Jordan-Young concludes that children with and without CAH are more alike than different. But in my view, she underestimates the differences between girls with $\mathrm{CAH}$ and their unaffected peers in two domains.

Although the data are mixed, girls with CAH seem to be better at mentally rotating shapes than are unaffected girls. The results are clearer for toy preferences: when asked to choose from various 'masculine', 'feminine' and 'neutral' toys, girls with CAH show more interest in masculine and less interest in feminine toys than girls who are unaffected. Boys with and without $\mathrm{CAH}$ are indistinguishable in their choices.

Whether a toy is perceived as masculine or feminine, however, depends on who plays with it; as Jordan-Young notes, children's play preferences have changed over time. Some activities once seen as masculine, such as playing with construction toys and balls, are now seen as neutral and on a par with books and puzzles. Dolls, by contrast, have remained feminine. Toy-preference studies show that girls divide their time equally among masculine, feminine and neutral toys, whereas boys tend to eschew feminine ones. So the girls with $\mathrm{CAH}$ are acting like control boys. But we cannot tell whether that is because they prefer masculine toys or are taking less interest in feminine ones. The way such questions are posed affects where one searches for answers.

So why do boys avoid dolls? They learn early that they will pay a social price for showing 'deviant' feminine interests. Girls can like the same toys as boys with little fear 
of negative social consequences, as demonstrated by the different connotations of 'sissy' and 'tomboy'. For girls with $\mathrm{CAH}$, there is another social issue: many undergo genital surgery in infancy and have impaired fertility. Girls' knowledge about their condition may trigger concerns about their femininity and lead to an avoidance of toys such as dolls.

To some extent, both books are brooms that sweep too clean. I contend that one cannot dismiss sex differences in mental rotation of three-dimensional objects as ill-documented or easily reversed, as both authors do. The difference is robust and difficult to neutralize; its precursors are seen in infancy. Laying such distinctions only at the doorstep of social psychology - in different expectations of the two sexes, for example closes off inquiry into underlying cognitive processes. Similarly, there is almost nothing about sex differences in mathematics and science in Jordan-Young's book, and only a cursory treatment in Fine's.

I share both authors' conclusions that the jury is still out over whether hormonal and neural sex differences are linked to behavioural divergence. I also agree that social context is often a more likely source of sex differences. Most behavioural sex differences are small, and there is no direct mapping between a behaviour and a set of neural mechanisms. Different neural mechanisms can be responsible for the same behaviour.

It is no bad thing that there are many hypotheses still to test. Eventually, unsupported preconceptions about what counts as masculine and feminine will be discarded. Until then, people such as Fine and JordanYoung are just who we need.

Virginia Valian is professor of psychology and co-director of the Gender Equity Project at Hunter College, City University of New York, New York 10065, USA.

e-mail:virginia.valian@hunter.cuny.edu

\section{Answers from the Atacama}

\section{A Chilean film juxtaposes astronomy with the search for those killed under Augusto Pinochet, finds Alison Abbott.}

$\mathrm{T}$ The Atacama Desert in northern Chile is the driest place on Earth. Decades can pass with no rain. Patricio Guzmán tells the stories of the people who are searching in its arid expanse in his film Nostalgia de la Luz (Nostalgia for the Light) - winner of the 2010 European Film Academy award for best documentary and now showing in selected cinemas in Europe. On the desert's mountain tops, astronomers look skyward, hunting for cosmological truths. On its plains, others look towards the ground, hunting for political truths.

Astronomers love the Atacama. Its dryness and clear skies give them an unimpeded view of deep space. Since the mid-1960s, they have been building ever-more powerful telescopes there with which to gaze ever farther into the cosmos. Piecing together the history of the Universe from the ancient light of distant stars, they are largely unaware of the women below on the desert floor, digging - sometimes with their bare hands - for the remains of loved ones killed during the regime of dictator Augusto Pinochet in the 1970s.

Nostalgia de la Luz interweaves the stories of these two searches - one addressing modern history on a heartbreakingly human scale, the other deep history on a grandiose and edifying scale. Other scientific investigations also feature, including archaeology. It is a slow, poetic film that contemplates existential questions: where we
For more on the spirit of observatories: go.nature.com/ehdlon

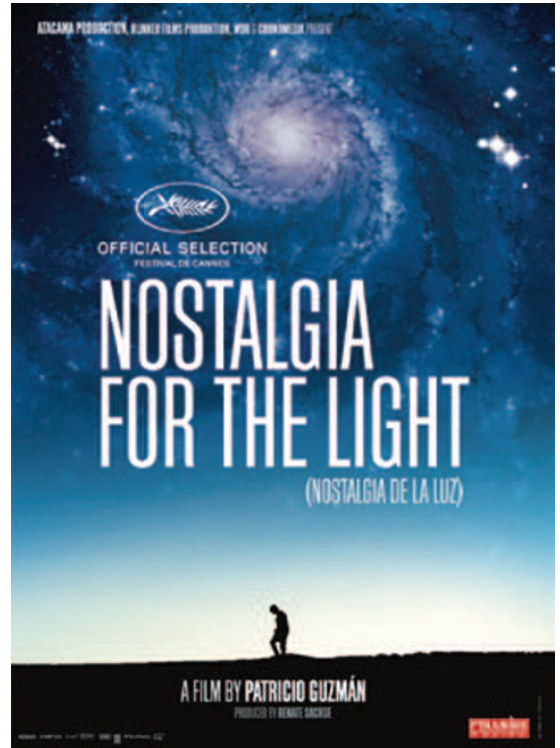

Nostalgia de la Luz

DIRECTED BY PATRICIO GUZMÁN

In some independent cinemas in Europe.

came from, where we are going and how we come to terms with the pain of the present. It is compelling, thanks to the characters that the director has found to explain their quests.

Gaspar is an articulate young Chilean astronomer working at the Cerro Tololo observatory, who can answer many questions about cosmic history but few about his country's recent past, when thousands disappeared or were killed and traces of their fate covered up. Lautaro is an older archaeologist who followed the trails of ancient civilizations through the desert for decades, finding their mummified dead in the desiccating atmosphere. Now he teaches the searching women how to recognize from the surface grains whether a human body might lie below the sand.

Also featured is Luís. He spent years in one of Pinochet's concentration camps in the desert, where he learnt about astronomy from a fellow political prisoner. Stargazing helps him not to forget that time, he says. Miguel, an architect, survived five such camps. He committed their layouts to memory and drew them up precisely when he was freed, so that Chileans would never be able to deny their existence.

Towards the end of the dictatorship, Pinochet's soldiers dug up mass graves and dumped evidence of the massacres in the sea. The film follows Victoria and Violeta, who talk movingly about their continuing search for their loved ones. They have found fragments of their bones, smashed by the digging machinery, which has fed their determination to find out what happened.

And there is Valentina, whose mother and father were among those who disappeared, who became an astronomer after the grandparents who raised her taught her to observe the night sky. Understanding the infinite Universe, she says, has given her a comforting perspective on her loss.

Guzmán, the film's director, is himself a refugee from Pinochet's Chile, and now lives in France. Most of his films have been political, and this venture into science provides him with metaphors of immense power with which to explore this theme. Nostalgia de la Luz will also confront scientists with connections that they have not previously imagined. If only, the searching women say, the telescopes could instead point downwards to help them.
Alison Abbott is Nature's European correspondent. 